Gut, 1979, 20, 957-962

\title{
Big and little gastrin responses to food in normal and ulcer subjects
}

\author{
I. L. TAYLOR, G. J. DOCKRAY ${ }^{1}$, J. CALAM, AND R. J. WALKER \\ From the Department of Physiology, University of Liverpool, and The Gastrointestinal Unit, Walton \\ Hospital, Liverpool
}

SUMMARY In normal, duodenal ulcer, and gastric ulcer subjects the two main forms of gastrin, G17 and G34, were estimated by radioimmunoassay in fasting serum and after feeding. Two antisera were used: one showing high specificity for G17, the other specific for the common $\mathrm{COOH}$-terminus of G17 and G34 and so allowing estimation of G34 by difference. Basal G17 was similar in gastric ulcer, duodenal ulcer, and normal subjects and the increases of G17 after feeding were also similar in these groups. In contrast, basal G34 was similar in normal and duodenal ulcer subjects but raised in gastric ulcer subjects. After a meal the G34 concentration in both gastric and duodenal ulcer patients was significantly higher than normal. It is concluded that the higher post-prandial gastrin responses in peptic ulcer that have been previously described are due largely to increased G34.

It is established that gastrin is responsible for the fulminating peptic ulceration seen in patients with the Zollinger-Ellison syndrome (Gregory et al., 1967). However, the importance of gastrin in the pathogenesis of peptic ulcer not associated with gastrinoma is unclear. Patients with both duodenal (Trudeau and McGuigan, 1970; Walsh and Grossman, 1973) and gastric ulcer (Korman et al., 1972) have higher than normal gastrin responses to a meal. However, patients with duodenal ulcer tend to have higher than normal basal and maximal rates of gastric acid secretion, whereas gastric ulcer patients have lower than normal basal and maximal acid outputs (Wormsley and Grossman, 1965). Interpretation of these findings is complicated by the fact that gastrin circulates in several different molecular forms, and that frequently the antibodies used in gastrin radioimmunoassays (RIA) are unable to distinguish between these forms (Walsh, 1974; Stadil et al., 1975). After a meal two forms of gastrin predominate in the circulation. These correspond to peptides with 34 amino-acid residues (big gastrin, G34) and 17 amino-acid residues (little gastrin, G17), that have been isolated from human

${ }^{1}$ Address for correspondence: Dr G. J. Dockray, Physiological Laboratory, University of Liverpool, Liverpool L69 3BX.

Received for publication 16 May 1979 gastrinomas and hog antral mucosa (Gregory and Tracy, 1964, 1972). G34 and G17 may be sulphated or unsulphated at the tyrosine residue, which is in the sixth amino-acid position counting unconventionally from the carboxyl-terminus. Other circulating forms of gastrin have been described (big, big gastrin, component I, minigastrin, etc.) but these either do not increase after feeding or occur only in low concentrations and are unlikely to make more than a minor contribution to circulating gastrin biological activity (Stadil et al., 1975).

Walsh and co-workers (1976) have studied the actions of G17 and G34 on gastric acid secretion in patients with duodenal ulcer and have shown that circulating $\mathrm{G} 17$ is six to eight times more potent than G34 in stimulating acid secretion. A relatively minor increase in the ratio of G17 to G34 could therefore contribute to the increased acid secretion seen in duodenal ulcer. A change in this ratio would not be detected by RIA employing antisera with specificity for the carboxyl-terminus of G17, as these antisera do not usually distinguish between G17 and G34 (Walsh, 1974; Stadil et al., 1975). Previous attempts to estimate separately the concentrations of G17 and G34 have involved partitioning the two forms, usually by molecular sieving on columns of G50 Sephadex and then estimation of the gastrin concentration in successive fractions by RIA (Dockray and Walsh, 1975; Stadil 
et al., 1975). Such fractionation techniques are frequently insensitive and time consuming, and in the past only small numbers of samples have been studied. However, recently we described an antiserum that has almost absolute specificity for G17 and cross-reacted with other molecular forms or fragments of gastrin less than 0.003 relative to $\mathbf{G 1 7}$; we showed this antiserum could be used in a specific RIA for G17 in serum (Dockray and Taylor, 1976). This method, therefore, permits direct measurement of G17-like immunoreactivity (G17-LI) in blood without prior fractionation and without the problems that arise from cross-reactivity with other molecular forms or fragments of gastrin. We report here on the application of this assay to the study of gastrin responses to a meal in normal subjects and in patients with duodenal ulcer and gastric ulcer.

\section{Methods}

\section{SUBJECTS}

In an initial study basal serum gastrin in 27 normal subjects (mean age 53 years), 13 duodenal (mean age 58 years) and 15 gastric ulcer (mean age 50 years) patients was analysed against a standard prepared in gastrin-free serum. Subsequently, the gastrin responses to food were measured in a second set of subjects consisting of groups of age and sex matched normal subjects and duodenal ulcer patients ( 22 male, three female, mean age 34 years) and in a small group of gastric ulcer patients (three female, two male, mean age 58 years). The normal subjects were students, laboratory and hospital staff, and were without gastrointestinal symptoms and had no family histories of peptic ulcer disease. In all the gastric and duodenal ulcer patients the presence of active ulceration was confirmed endoscopically within one month of the studies and all patients were symptomatic with two months of study. Routine biopsies of the gastric ulcers, all of which occurred in the body or fundus of the stomach, revealed that none was malignant. None of the patients had received $\mathrm{H}^{2}$-antagonists, but antacids were allowed up to the day before the study. In 21 of the 25 duodenal ulcer patients who received the test meal, basal and maximal acid secretion in response to pentagastrin $(6 \mu \mathrm{g} / \mathrm{kg}$, subcutaneously) was measured after an overnight fast. All subjects gave informed consent and the studies were approved by the Human Studies Committee at Walton Hospital, Liverpool.

STANDARD MEAL

Each subject fasted from midnight. The following morning blood samples were taken through an indwelling intravenous needle 15 and five minutes before the subject ate a standard meal. The meal consisted of two hard boiled eggs, a piece of dry toast, and a cup of beef extract (two Oxo cubes in $120 \mathrm{ml}$ of warm water) and was eaten over a period of 10 minutes. A blood sample was taken when the subject completed the meal and thereafter samples were taken at 10 minute intervals for 50 minutes, and at 15 minute intervals for another hour. Blood samples were allowed to clot at $4^{\circ}$, centrifuged (2000 x $g, 10$ minutes) and serum separated and stored at $-20^{\circ}$ before radioimmunoassay for gastrin.

\section{RADIOIMMUNOASSAY}

Serum gastrin concentrations were estimated by RIA according to published methods (Yalow and Berson, 1970; Walsh, 1974). Two antisera with different specificities were used. One antiserum (L6) has been shown to have almost absolute specificity for G17 and shows negligible cross-reactivity with G34 and with fragments of G17 with amino acid deletions at either carboxyl- or amino-termini (Dockray and Taylor, 1976). The second antiserum (1296) is specific for the carboxyl-terminus of G17 and therefore measures G17, G34, and other gastrin variants with a carboxyl-terminus similar to G17 (Dockray and Walsh, 1975). As G17 and G34 are the predominant circulating forms after a meal an indirect estimate of the $\mathrm{G} 34$ concentration in serum (estimated-G34) can be obtained from the difference between assays made on the same serum sample with L6 and 1296. Pure natural human unsulphated G17 was used as a standard for assays. However, the immunochemical potency of $\mathrm{G} 34$ relative to $\mathrm{G} 17$ with 1296 is about 0.6 and the estimated-G34 concentration was therefore corrected to take account of this difference in immunopotency (Dockray and Walsh, 1975).

A significant fraction of gastrin immunoreactivity in basal serum can be attributed to non-specific interference by serum constituents such as proteins (Dockray et al., 1975; Rehfeld et al., 1977), and a true estimate of basal gastrin concentration needs to take this into account. We overcame this problem by measuring basal serum G17-LI and estimated-G34 concentrations in 27 normal, 13 duodenal and 15 gastric ulcer subjects against standards containing pooled human serum rendered free of immunoreactive gastrin by specific immunoadsorption (Dockray and Taylor, 1976). As this non-specific component does not alter after a meal the incremental response (postprandial minus basal) gives an accurate measure of change in true gastrin immunoreactivity (Dockray and Taylor, 1976).

Results unless otherwise stated are given as mean \pm standard error of the mean and comparisons 
Table 1 Basal serum G17-LI and estimated-G34 in duodenal ulcer, gastric ulcer, and normal subjects assayed against standards containing pooled human serum stripped of gastrin by immuno-adsorption

\begin{tabular}{|c|c|c|c|c|c|c|}
\hline \multirow[b]{2}{*}{ Group } & \multirow[b]{2}{*}{ No. } & \multirow{2}{*}{$\begin{array}{l}\text { Mean age } \\
(y r)\end{array}$} & \multicolumn{2}{|c|}{$G 17-L I(p M)$} & \multicolumn{2}{|c|}{ Estimated-G34 (pM) } \\
\hline & & & Median & $M e a n \pm S E$ & Median & $M e a n \pm S E$ \\
\hline $\begin{array}{l}\text { Normal } \\
\text { Duodenal ulcer } \\
\text { Gastric ulcer }\end{array}$ & $\begin{array}{l}27 \\
13 \\
15\end{array}$ & $\begin{array}{l}53 \\
58 \\
50\end{array}$ & $\begin{array}{l}7 \\
6 \\
5\end{array}$ & $\begin{array}{l}9 \pm 1 \\
8 \pm 2 \\
6 \pm 1\end{array}$ & $\begin{array}{r}16 \\
9 \\
23\end{array}$ & $\begin{array}{l}17 \pm 4 \\
11 \pm 4 \\
28 \pm 4^{*}\end{array}$ \\
\hline
\end{tabular}

*Significantly different from normal, $\mathrm{P}<0.05$.

were made by Student's paired or unpaired $t$ test, whichever was appropriate. Possible relationships between serum gastrin and acid secretion were analysed by linear regression.

\section{Results}

BASAL SERUM GASTRIN CONCENTRATIONS

Table 1 shows basal G17-LI and estimated-G34 concentrations in serum from normal, gastric, and duodenal ulcer subjects assayed against standards containing pooled human serum stripped of gastrin by specific immunoadsorption in order to eliminate nonspecific interference by serum constituents. In these circumstances there were no significant differences between duodenal ulcer and normal subjects in the basal serum G17-LI and estimatedG34 concentrations. In contrast, basal estimatedG34 concentrations were significantly higher than normal in gastric ulcer patients, but basal G17-LI concentrations were similar to normal.

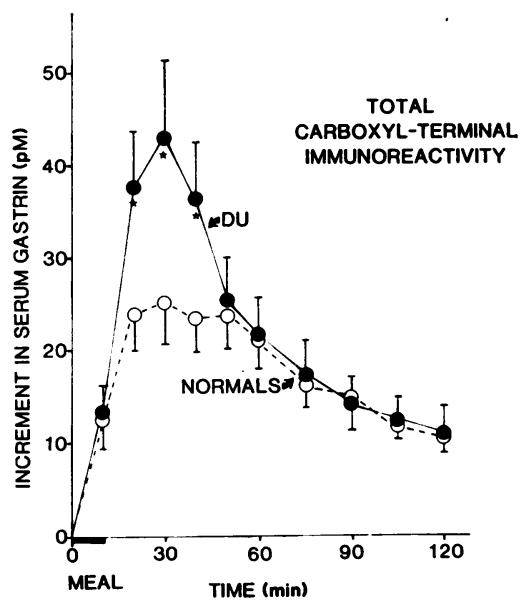

Fig. 1 Increment in serum total carboxyl-terminal immunoreactivity in response to a standard meal in 25 normal (o - - - o) and 25 duodenal ulcer (osubjects. In this and the following figures vertical bars indicate the standard error of the mean, *Significant difference from normal, $\mathrm{P}<0.05$

\section{FEEDING STUDIES}

\section{Duodenal ulcer}

In both duodenal ulcer and normal subjects the increment in serum gastrin concentration measured by 1296 and L6 rose to a peak 20 to 30 minutes after the standard meal (Figs 1 and 2). The peak concentration of G17-LI was about $30 \%$ higher in duodenal ulcer $(18 \pm 4 \mathrm{pM})$ than in normal subjects $(13.5 \pm 3$ pM), but the difference was not statistically significant (Table 2, Fig. 2). In contrast, at 20, 30, and 40 minutes after the meal the increment in total carboxyl-terminal gastrin immunoreactivity measured by 1296 was significantly higher in duodenal ulcer than in normal subjects $(\mathrm{P}<0.05)$ (Fig. 1). Moreover, the proportion of immunoreactive gastrin measured by L6 (G17-LI) to that measured by 1296 (total carboxyl-terminal immunoreactive gastrin) at the time of peak total carboxyl-terminal immunoreactive gastrin response was significantly lower in the duodenal ulcer patients (Table 2). The concentration of estimated-G34 (Fig. 3) reached a peak at 30 minutes after feeding in duodenal ulcer $(36 \cdot 5 \pm 7 \cdot 2$ $\mathrm{pM}$ ), and at 50 minutes after feeding in normal subjects $(20.5 \pm 4 \mathrm{pM})$. The peak estimated-G34 response was significantly greater in the duodenal ulcer patients $(\mathrm{P}<0.05)$ (Table 2$)$.

In 21 of the duodenal ulcer subjects the mean basal rate of acid secretion was $6 \cdot 2 \pm 1.1 \mathrm{mEq} / \mathrm{h}$ and the maximal rate of acid secretion was $43 \cdot 2 \pm 2 \cdot 8$

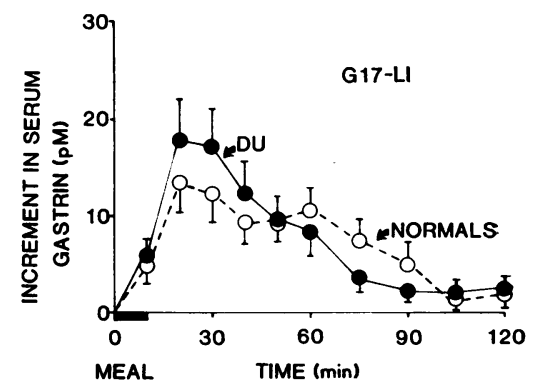

Fig. 2 Increment in serum G17-LI in response to a standard meal in normal (o-- - o) and duodenal ulcer $(\mathrm{o}-\mathrm{o})$ subjects 
Table 2 Peak increment in G17-LI and estimated -G34 in normal subjects and duodenal and gastric ulcer patients

\begin{tabular}{lllll}
\hline Group & No. & $\begin{array}{l}\text { Peak G17-LI } \\
(p M)\end{array}$ & $\begin{array}{l}\text { Peak } \\
\text { estimated-G34 } \\
(p M)\end{array}$ & $\begin{array}{l}\text { \% G17 relative to total COOH-terminal } \\
\text { immunoreactivity at peak response }\end{array}$ \\
\hline Normal & 25 & $13 \cdot 5 \pm 3$ & $20 \cdot 5 \pm 4 \cdot 0$ & $58 \cdot 4 \pm 9 \cdot 1$ \\
Duodenal ulcer & 25 & $18 \cdot 0 \pm 4$ & $36 \cdot 5 \pm 7 \cdot 2^{*}$ & $41 \cdot 5 \pm 4 \cdot 0^{*}$ \\
Gastric ulcer & 5 & $17 \cdot 0 \pm 5$ & $62 \cdot 0 \pm 15^{*}$ & $12 \cdot 1 \pm 5 \cdot 5 \dagger$ \\
\hline
\end{tabular}

* Significantly different from normal subjects $(P<0.05)$.

†Significantly different from normal subjects and duodenal ulcer patients $(P<0.05)$.

$\mathrm{mEq} / \mathrm{h}$. There was no statistically significant correlation between fasting G17-LI, estimated-G34, or total carboxyl-terminal immunoreactivity on the one hand, and basal acid secretion on the other. Neither was there a statistically significant correlation between peak postprandial total carboxyl-terminal immunoreactive gastrin, G17-LI or estimated-G34 concentrations, and basal or maximal acid output.

\section{GASTRIC ULCER}

In patients with gastric ulcer the peak postprandial increment in carboxyl-terminal immunoreactivity $(49.0 \pm 11.5 \mathrm{pM})$ was significantly higher than normal $(25.2 \pm 4.5 \mathrm{pM})$ and the response was more prolonged. At 120 minutes after the meal the total carboxyl-terminal immunoreactivity was more than three times higher in gastric ulcer compared with normal subjects (Fig. 4). However, the increase in serum G17-LI in the gastric ulcer patients $(17 \pm 5$ pM) was similar to that seen in normal subjects (13.5 \pm 3 pM) (Fig. 5). Thus the higher carboxylterminal immunoreactivity in gastric ulcer can be attributed to an increase in the estimated-G34

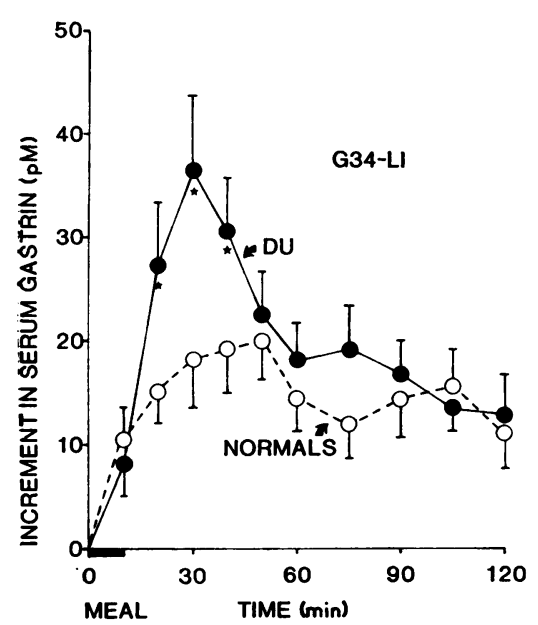

Fig. 3 Increment in serum estimated-G34 (G34-LI) in response to a standard meal in normal $(0---0)$ and duodenal ulcer subjects (o fraction (Fig. 6). Indeed, estimated-G34 concentrations were significantly higher than normal during all time periods except two. The relative proportion of G17-LI at the time of peak response measured by 1296 was significantly lower in the gastric ulcer patients than in either the patients with duodenal ulcer or the normal subjects (Table 2).

\section{Discussion}

In this study we have estimated G17 and G34 concentrations in the circulation of peptic ulcer patients and normal subjects by RIA employing two antisera with different specificities. In previous studies fractionation of serum samples by gel filtration has been used to obtain separate estimates of G17 and G34 (Dockray and Walsh, 1975; Stadil et al., 1975). However, the present approach lends itself to processing large numbers of samples, and has permitted study of the responses in larger numbers of subjects, and in greater detail, than previously attempted.

There have been several other attempts to measure

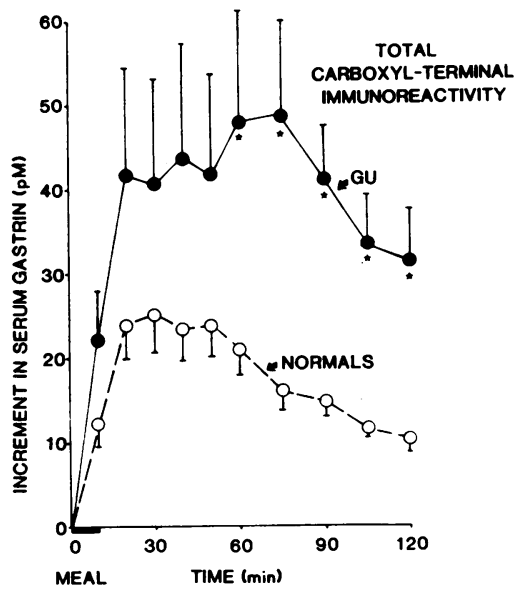

Fig. 4 Increment in serum total carboxyl -terminal immunoreactivity in response to a standard meal in 25 normal (o- - - o) and 5 gastric ulcer (0_— subjects 


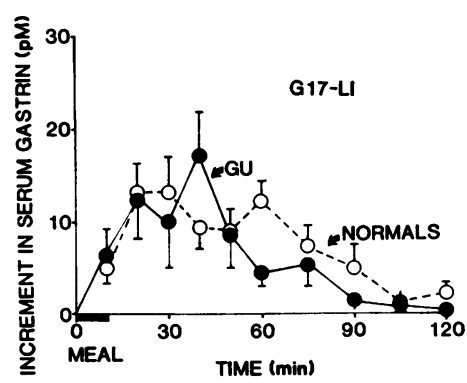

Fig. 5 Increment in serum G17-LI in response to a standard meal in normal (o-- - o) and gastric ulcer (o- $\longrightarrow$ ) subjects

circulating forms of gastrin by means of region specific antisera. Thus McGuigan and Herbst (1974) suggested that antisera specific for the aminoterminal portion of $\mathrm{G17}$ could be used to measure G17 specifically. However, an amino-terminal fragment of G17 has been found in the serum of patients with ZES (Dockray and Walsh, 1975), so that measurements made with such antisera cannot be attributed to immunoreactive G17 alone. Hansky et al. (1974) found significant differences between duodenal ulcer and normal subjects in fasting serum gastrin measured with two antisera-one of which cross-reacted with the unsulphated form of G17 but not the sulphated form, and the other cross-reacted equally with sulphated and unsulphated G17. The G17 specific antiserum (L6) used in the present study does not cross-react with G34 or with carboxyl- and amino-terminal fragments of G17 and shows almost equal immunoreactivity with sulphated and unsulphated G17 (Dockray and Taylor, 1976). The difference in concentration of immunoreactive gastrin measured by L6 and 1296 (carboxyl-terminal specific) can be ascribed to components with carboxyl-terminal immunoreactivity other than G17. Previous studies have established that the most important of these components is G34 (Stadil et al., 1975). We designate this fraction of circulating gastrin 'estimated-G34', although we recognize that other components which occur in low concentration - for example, component I and minigastrin (G14) will be included in it.

In normal subjects 60 to $70 \%$ of the immunoreactivity in fasting serum measured by 1296 and L6 was not removed by immunoadsorption (Dockray and Taylor, 1976); this fraction can be accounted for by factors causing non-specific inhibition of binding of label to antibody. The non-specific component did not increase after a meal, so that the use of incremental responses gives an accurate measure of change in the gastrin immunoreactivity (Dockray

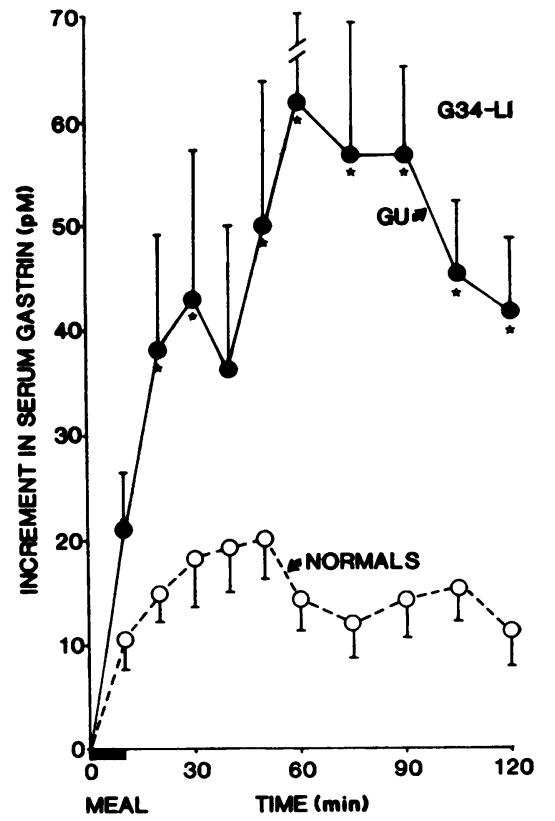

Fig. 6 Increment in serum estimated-G34 (G34-LI) in response to a standard meal in normal (o- $\left.-0_{0}\right)$ and gastric ulcer (o_- o) subjects

and Taylor, 1976). The major contribution made by non-specific interfering substances in the measurement of serum gastrin concentration in normal subjects obviously complicates the comparison of basal serum gastrin in duodenal ulcer and normal subjects. The use of hormone free serum to construct standard curves largely overcomes this difficulty and the present findings suggest little difference in fasting concentrations of G17 and G34 between duodenal ulcer and normal subjects. However, patients with gastric ulcer have increased estimatedG34 concentrations in their basal serum, but normal G17-LI concentrations.

The results of this study confirm previous findings that, after a meal, total circulating immunoreactive gastrin is higher in duodenal ulcer than in normal subjects (Trudeau and McGuigan, 1970; Walsh and Grossman, 1973). Our results extend these observations and indicate that both G17 and G34 are raised. However, there was a considerable overlap in concentrations of G17-LI and estimated-G34 in serum of normal and duodenal ulcer subjects, and only the difference in estimated-G34 achieved statistical significance. The contribution of G17-LI to total carboxyl-terminal immunoreactivity at the time of peak response was significantly lower in duodenal ulcer compared with normal subjects, indicating that estimated-G34 is a higher proportion 
of circulating gastrin in duodenal ulcer. Our finding of normal postprandial serum G17-LI concentrations in duodenal ulcer patients differs from that of Stadil et al. (1975), who reported that the greater total gastrin response to a meal in these patients was mainly due to an increase in G17 concentrations. However, in their study, the duodenal ulcer patients were not studied individually. Instead, pooled samples for eight different subjects were fractionated on Sephadex. Thus it is possible that one subject could influence the pattern of components disproportionately.

It is established that basal and maximal rates of acid secretion are higher in duodenal ulcer than in normal subjects. In addition, the intragastric $\mathrm{pH}$ is lower after a meal in these patients compared with normal subjects. In the present study basal (6.2 $\mathrm{mEq} / \mathrm{h})$ and maximal $(43 \mathrm{mEq} / \mathrm{h})$ rates of acid secretion in the duodenal ulcer group were comparable with those reported in the literature (Wormsley and Grossman, 1965). Acid is known to suppress the secretion of gastrin in normal subjects (Walsh et al., 1975). Thus, the raised gastrin concentration in duodenal ulcer suggests a failure of acid inhibition and is consistent with experimental observations of an impairment of the mechanism by which acid suppresses gastrin in response to feeding in duodenal ulcer (Walsh et al., 1975).

Walsh et al. (1976) have constructed doseresponse curves for the relationships between acid secretion and circulating concentrations of G17 and G34 during intravenous infusion in duodenal ulcer subjects. From these data we estimate that the peak postprandial concentration of $\mathrm{G} 17$ in duodenal ulcer (18 pM) could stimulate 40 to $50 \%$ of maximal acid output. In contrast, the peak concentration of G34 (36 pM) could stimulate about $20 \%$ or less of maximal acid output. Precisely comparable data on the biological potency of G17 and G34 in normal subjects are not yet available.

In gastric ulcer patients the increased postprandial total carboxyl-terminal immunoreactivity can be completely explained by an increase in estimatedG34, as the G17-LI response was almost identical with that seen in the normal subjects. Because G17 is the principal biologically active form of gastrin (Walsh et al., 1976), the low rate of acid secretion seen in gastric ulcer does not result from diminished secretion of G17. However, the disproportionate increase in estimated-G34 concentrations in the serum of gastric ulcer patients after a meal suggests an altered rate of secretion or metabolism of one or other form of gastrin.

We are indebted to Mrs Elaine Clarke, Miss Carol ggins, and Mrs Brenda Harris for skilled technical assistance. Professor R. A. Gregory and Dr H. J. Tracy generously donated samples of pure natural G17-I and G34-I. Dr John Walsh kindly donated antiserum 1296. Dr I. L. Taylor was the recipient of a Nuffield Research Fellowship.

\section{References}

Dockray, G. J., Debas, H. T., Walsh, J. H., and Grossman, M. I. (1975). Molecular forms of gastrin in antral mucosa and serum of dogs. Proceedings of the Society for Experimental Biology and Medicine, 149, 550-553.

Dockray, G. J., and Taylor, I. L. (1976). Heptadecapeptide gastrin: Measurement in blood by specific radioimmunoassay. Gastroenterology, 71, 971-977.

Dockray, G. J., and Walsh, J. H. (1975). Amino terminal gastrin fragment in serum of Zollinger-Ellison syndrome patients. Gastroenterology, 68, 222-230.

Gregory, R. A., Grossman, M. I., Tracy, H. J., and Bentley, P. H. (1967). Nature of gastric secretagogue in ZollingerEllison tumours. Lancet, 2, 543-544.

Gregory, R. A., and Tracy, H. J. (1964). The constitution and properties of two gastrins extracted from hog antral mucosa. Part 1. The isolation of two gastrins from hog antral mucosa. Gut, 5, 103-117.

Gregory, R. A., and Tracy, H. J. (1972). Isolation of two 'big gastrins' from Zollinger-Ellison tumour tissue. Lancet, 2, 797-799.

Hansky, J., Soveny, C., and Korman, M. G. (1974). Studies with two gastrin antisera of different specificity for gastrins I and II. Digestion, 10, 97-107.

Korman, M. G., Soveny, C., and Hansky, J. (1972). Gastrin studies in gastric ulcer. Gut, 13, 166-169.

McGuigan, J. E., and Herbst, C. A. (1974). Separate immunochemical measurements of heptadecapeptide and big gastrins by use of region-specific antibodies to gastrin (Abstract). Gastroenterology, 66, 854.

Rehfeld, J. F., Schwartz, T. W., and Stadil, F. (1977). Immunochemical studies on macromolecular gastrins. Gastroenterology, 73, 469-477.

Stadil, F., Rehfeld, J. F., Christiansen, L. A., and Malmström, J. (1975). Patterns of gastrin components in serum during feeding in normal subjects and duodenal ulcer patients. Scandinavian Journal of Gastroenterology, 10, 863-868.

Trudeau, W. L., and McGuigan, J. E. (1970). Serum gastrin levels in patients with peptic ulcer disease. Gastroentero$\log y, 59,6-12$.

Walsh, J. H. (1974). Radioimmunoassay of gastrin. In Nuclear Medicine in Vitro, pp. 17 and 213-248. Edited by B. Rothfeld. Lippincott: Philadelphia.

Walsh, J. H., and Grossman, M. I. (1973). Circulating gastrin in peptic ulcer disease. Mount Sinai Journal of Medecine, 40, 374-381.

Walsh, J. H., Isenberg, J. I., Ansfield, J., and Maxwell, V. (1976). Clearance and acid-stumulating action of human big and little gastrins in duodenal ulcer subjects. Journal of Clinical Investigation, 57, 1125-1131.

Walsh, J. H., Richardson, C. T., and Fordtran, J. S. (1975). $\mathrm{pH}$ dependence of acid secretion and gastrin release in normal and ulcer subjects. Journal of Clinical Investigation, 55, 462-468.

Wormsley, K. G., and Grossman, M. I. (1965). Maximal histolog test in control subjects and patients with peptic ulcer. Gut, 6, 427-435.

Yalow, R. S., and Berson, S. A. (1970). Radioimmunoassay of gastrin. Gastroenterology, 58, 1-14. 